\title{
Abstraction of Seepage into Drifts
}

SAND 2000- $2389 \mathrm{C}$

\author{
Michael L. Wilson \\ Sandia National Laboratories \\ P.O. Box 5800, MS-0778 \\ Albuquerque, NM 87185-0778 \\ mlwilso@sandia.gov \\ Clifford K. Ho \\ Sandia National Laboratories \\ P.O. Box 5800, MS-0735 \\ Albuquerque, NM 87185-0735 \\ ckho@sandia.gov
}

\section{Introduction}

A total-system performance assessment (TSPA) for a potential nuclear-waste repository requires an estimate of the amount of water that might contact waste. This paper describes the model used for part of that estimation in a recent TSPA for the Yucca Mountain site. The discussion is limited to estimation of how much water might enter emplacement drifts; additional considerations related to flow within the drifts, and how much water might actually contact waste, are not addressed here. The unsaturated zone at Yucca Mountain is being considered for the potential repository, and a drift opening in unsaturated rock tends to act as a capillary barrier and divert much of the percolating water around it. For TSPA, the important questions regarding seepage are how many waste packages might be subjected to water flow and how much flow those packages might see.

Because of heterogeneity of the rock and uncertainty about the future (how the climate will evolve, etc.), it is not possible to predict seepage amounts or locations with certainty. Thus, seepage is treated as a stochastic quantity in TSPA simulations, with the magnitude and spatial distribution of seepage sampled from uncertainty distributions. The distillation of the essential components of process modeling into a form suitable for use in TSPA simulations is referred to 
as abstraction. In the following sections, seepage process models and abstractions will be summarized and then some illustrative results will be presented.

\section{Development of Uncertainty Distributions for Seepage}

The seepage process modeling that forms the basis for the seepage abstraction is documented in two Yucca Mountain Project reports, Seepage Calibration Model and Seepage Testing Data and Seepage Model for PA Including Drift Collapse. ${ }^{2}$ The former report contains results of some of the seepage testing at one niche (a side tunnel off the main tunnel) in the Exploratory Studies Facility underground at Yucca Mountain, and development of a calibrated computer model for the flow around and seepage into the opening. The model simulates flow through a fracture continuum with a heterogeneous permeability field. The latter report contains results of an extensive parameter study, with seepage amounts for varying percolation flux, fracture permeability, fracture capillary strength, and geostatistical parameters. The latter report also contains some analysis of how seepage is affected by drift degradation (that is, by the change in drift shape when rock blocks fall from the roof).

A third report, Abstraction of Drift Seepage, ${ }^{3}$ contains the details of how the process-model results were abstracted for use in TSPA simulations. As discussed in that report, examination of the parameter-study results ${ }^{2}$ reveals that computed seepage primarily depends on the input percolation flux and on the ratio of the geometric mean of the heterogeneous permeability field $(\bar{k})$ to the fracture van Genuchten $\alpha$ parameter. The process-model results that give the amount of seepage for various values of percolation flux and $\bar{k} / \alpha$ can be applied to TSPA simulations if the values of those parameters are known. 
The percolation flux is treated here as an unknown independent parameter; information for it comes from models for infiltration and unsaturated-zone flow, which will not be discussed. Information for $\vec{k}$ comes from air-permeability testing ${ }^{4}$ and information for $\alpha$ comes from calibration of seepage tests. ${ }^{1}$ It is worth noting that the niche used for calibration is in the Topopah Spring middle nonlithophysal hydrogeologic unit, whereas most of the potential repository is to be in the lower lithophysal unit. Also, the excavation-disturbed zone around niche openings could be different from emplacement drifts, because the niche was excavated with a road header, whereas the emplacement drifts are to be excavated by tunnel boring machine. The effect of these differences on the seepage results, if any, has not been evaluated as yet, but tests are currently being conducted in the lower lithophysal unit to determine how its seepage behavior compares to the middle nonlithophysal unit.

Values for $\bar{k} / \alpha$ are combined with the process-model seepage results (from reference 2 ) to obtain the estimated distribution of seepage for TSPA simulations. Seepage uncertainty is represented by uncertainty distributions for seepage fraction (the fraction of waste-package locations that have seepage), mean seep flow rate for locations with seepage, and standard deviation of the seep flow rate for locations with seepage. The distributions are developed by using computed seepage results for the "best-estimate" value of $\bar{k} / \alpha \cong 6 \times 10^{-11} \mathrm{~m}^{2} \cdot \mathrm{Pa}$ to develop a most-likely estimate of seepage, results for $\bar{k} / \alpha$ one order of magnitude higher to develop a minimum estimate, and results for $\bar{k} / \alpha$ one-half order of magnitude lower to develop a maximum estimate (note that lower values of $\bar{k} / \alpha$ correspond to greater amounts of seepage). The range of $\bar{k} / \alpha$ values represents uncertainty regarding how representative the best-estimate value is, especially for the Topopah Spring lower lithophysal hydrogeologic unit, where most of 
the emplacement drifts would be according to the present design. In developing the seepage estimates for the abstraction, the process-model seepage amounts are increased somewhat to compensate for possible effects of drift degradation and preferential pathways introduced by rock bolts. $^{3}$

The abstraction results for seepage fraction and mean seep flow rate as functions of impinging percolation flux are shown in Figure 1. Also shown in the lower graph is a curve for the flow rate corresponding to the amount of percolation flux above the footprint of a modeled drift segment. When the seep flow rate is below that curve, it indicates that flow is being diverted around the drift by the capillary-barrier effect. It can be seen that most flow is diverted around the drift except at very high percolation flux (above about $500 \mathrm{~mm} / \mathrm{yr}$ ) for the maximum estimate of seepage.

\section{Focusing of Flow above the Drifts}

The effect of intermediate-scale flow channeling (i.e., between the scales modeled by the sitescale unsaturated-zone-flow process model and the drift-scale seepage process model) is represented in the seepage abstraction ${ }^{3}$ by means of an uncertainty distribution for a flowfocusing factor. This factor is used to increase the percolation flux at some locations (representing drifts that happen to be located in flow channels), while at the same time decreasing the percolation flux at other locations to compensate. The effect of the flow-focusing factor is generally to increase the seep flow rate where there is seepage, but decrease the fraction of locations that have seepage (i.e., the seepage fraction). The total amount of seepage generally increases with flow focusing, because the seep flow rate increases by more than the seepage fraction decreases. 
The uncertainty distribution of the flow-focusing factor is based on $^{3}$ the spacing of actively flowing fractures implied by the calibrated site-scale flow fields. The method used to estimate the flowing-fracture spacing is a variant of a method proposed by Ho and Wilson, ${ }^{5}$ in which the fracture-matrix interface area in a dual-permeability flow model is used to back out a consistent geometry for the flowing fractures. The potential amount of flow focusing calculated in this way depends inversely on the amount of flow: Under drier conditions, flowing fractures are farther apart and there is a greater chance of a significant departure from the average on the $\sim 10-\mathrm{m}$ scale of the seepage model domain. The distribution developed for the flow-focusing factor has a lower bound of 1 (no focusing) and an upper bound ranging from about 10 to 50 for highinfiltration and low-infiltration cases, respectively. ${ }^{3}$

\section{Results}

To apply the seepage abstraction to TSPA simulations, percolation flux 5-m above the emplacement drifts is taken from thermohydrologic simulations ${ }^{6}$ and used as the input, in order to include some of the effects of heat from the waste. Five meters is far enough away from the drifts that the flow there is not significantly perturbed by the drift capillary barrier effect, and also far enough away that it is not usually within the boiling dry-out zone. Because of the latter, water can seep into the drifts throughout the heating period in the TSPA model. Potential reduction of seepage by evaporation or imbibition of water in the hot, dry rock in the $5 \mathrm{~m}$ above the drift is neglected.

To illustrate the seepage abstraction, a typical percolation-flux history was chosen (from reference 6) and seepage quantities were calculated for it. The resulting maximum and mostlikely histories of seepage fraction and mean seep flow rate are shown in Figure 2 . The 
minimum seepage history is not visible on the plot because it is zero everywhere (as shown in Figure 1, the minimum seepage estimate has a threshold percolation flux of approximately $100 \mathrm{~mm} / \mathrm{yr}$ for initiation of seepage). In a TSPA simulation, seepage at a location with this percolation-flux history would be sampled probabilistically between the "minimum" (zero) and "maximum" curves, with the sampling weighted toward the "most-likely" curve. Features of note that are visible in Figure 2 include climate changes to successively wetter climates at 600 and 2000 years, and a spike of percolation and seepage that results from thermally mobilized water after potential repository closure, which occurs at 50 years in the simulation. (Thermal effects are reduced before closure because active ventilation is assumed to carry away $70 \%$ of the heat.) Note also that even the maximum seepage curve is well below the percolation curve, indicating that most percolating water bypasses the drift rather than seeping in.

The effect of potential flow channeling on intermediate scales is illustrated in Figure 3, which shows the "most-likely" curves from Figure 2 along with curves calculated assuming flowfocusing factors $(F)$ of 5,10 , and 20 . Values above 20 are not used, because in the seepage abstraction the flow-focusing factor only goes up to about 20 for a location as wet as this one. It can be seen that the calculated seepage is increased substantially even for a flow-focusing factor of 5 , indicating that additional information on this effect could be valuable.

\section{Conclusions}

The model used for seepage into emplacement drifts in the recent TSPA for the Yucca Mountain Site Recommendation Consideration Report has been presented. This model contributes to the calculation of the quantity of water that might contact waste if it is emplaced at Yucca Mountain. Other important components of that calculation not discussed here include models for climate, 
infiltration, unsaturated-zone flow, and thermohydrology; drip-shield and waste-package degradation; and flow around and through the drip shield and waste package. The seepage abstraction model is stochastic because predictions of seepage are necessarily quite uncertain. The model provides uncertainty distributions for seepage fraction (fraction of waste-package locations with seepage) and seep flow rate as functions of percolation flux. In addition, effects of intermediate-scale flow channeling are included by means of a flow-focusing factor, which is also represented by an uncertainty distribution.

\section{Acknowledgments}

This work was supported by the Yucca Mountain Site Characterization Office as part of the Civilian Radioactive Waste Management Program, which is managed by the U.S. Department of Energy, Yucca Mountain Site Characterization Project. Sandia is a multiprogram laboratory operated by Sandia Corporation, a Lockheed Martin Company, for the United States Department of Energy under Contract DE-AC04-94AL85000.

\section{References}

1. S. Finsterle and R. C. Trautz, Seepage Calibration Model and Seepage Testing Data, MDLNBS-HS-000004 Rev. 00, Civilian Radioactive Waste Management System Management and Operating Contractor (CRWMS M\&O), Las Vegas, NV (2000).

2. C.-F. Tsang and G. Li, Seepage Model for PA Including Drift Collapse, MDL-NBS-HS000002 Rev. 00, CRWMS M\&O, Las Vegas, NV (2000).

3. M. L. Wilson, Abstraction of Drift Seepage, ANL-NBS-MD-000005 Rev. 00, CRWMS M\&O, Las Vegas, NV (2000). 
4. J. S. Y. Wang, In Situ Field Testing of Processes, ANL-NBS-HS-000005 Rev. 00, CRWMS M\&O, Las Vegas, NV (2000).

5. C. K. Ho and M. L. Wilson, "Calculation of Discrete Fracture Flow Paths in DualContinuum Models," in Proceedings of the Eighth International Conference on High-Level Radioactive Waste Management, pp. 375-377, American Nuclear Society, La Grange Park, IL (1998).

6. M. T. Itamura and N. D. Francis, Abstraction of NFE Drift Thermodynamic Environment and Percolation Flux, ANL-EBS-HS-000003 Rev. 00 ICN 01, CRWMS M\&O, Las Vegas, NV (2000). 

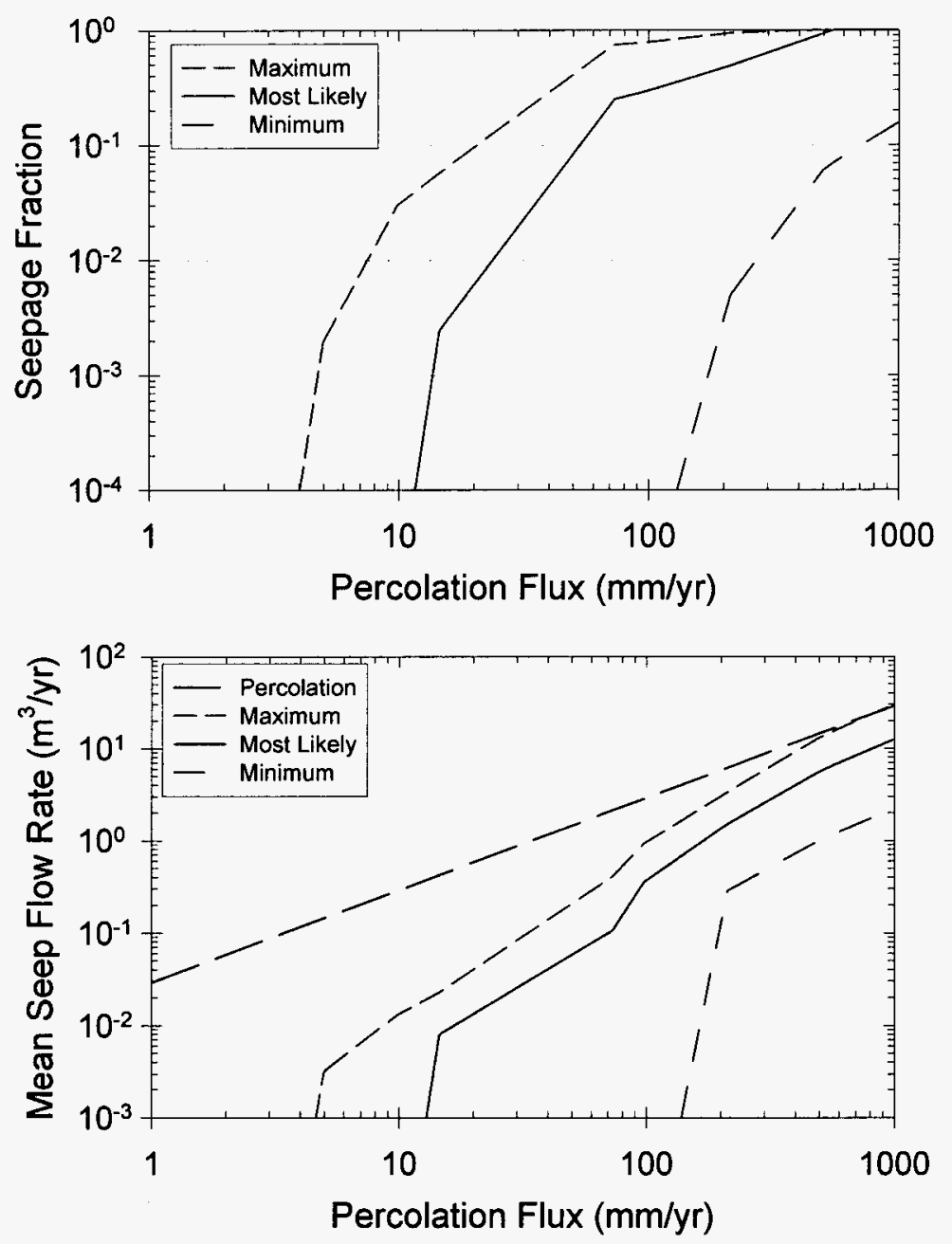

Figure 1. Bounds for seepage fraction (top) and mean seep flow rate (bottom) as functions of percolation flux (adapted from Figures 2 and 3 of reference 3 ). 

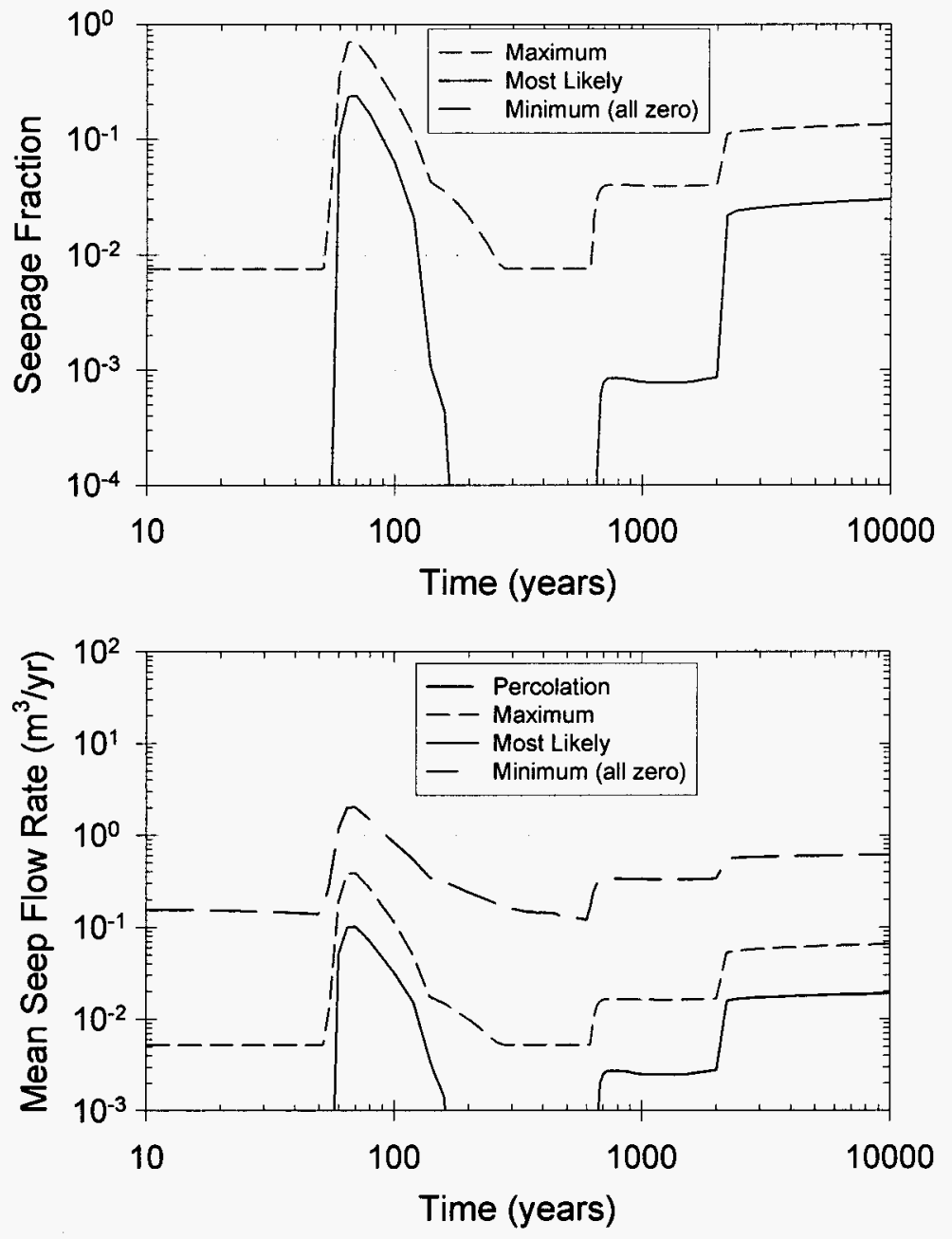

Figure 2. Time histories of the bounds for seepage fraction (top) and mean seep flow rate (bottom) for a selected location. 

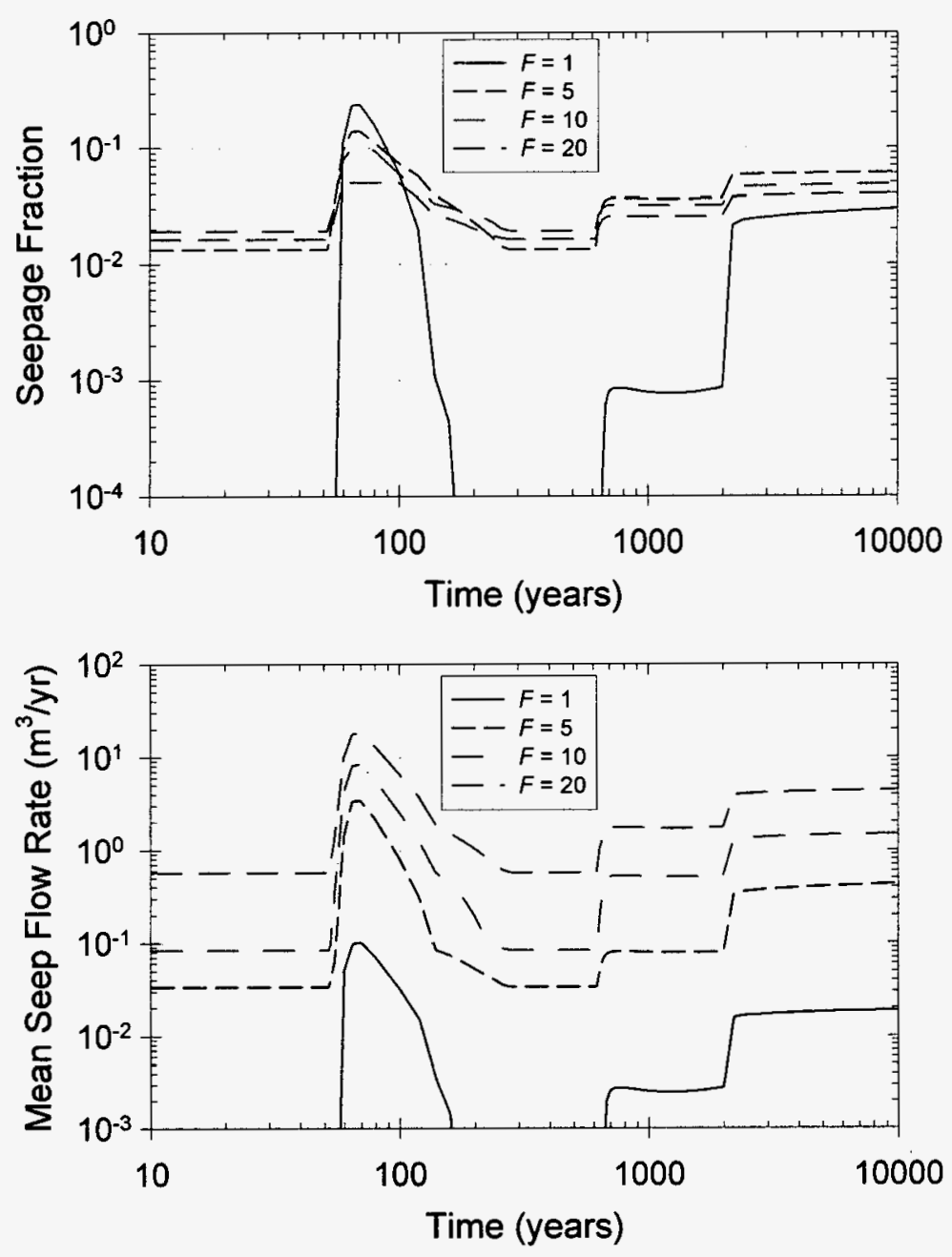

Figure 3. Time histories of seepage fraction (top) and mean seep flow rate (bottom), showing the effect of the flow-focusing factor. 